\title{
IMPLEMENTASI METODE PERMAINAN BAHASA GRAMMATICAL HUNTING DALAM PEMBELAJARAN BAHASA ARAB DI KELAS 3/1 MUTAWASITH KHOIRIYAH WITTAYA MULNITHI BETONG, YALA, THAILAND TAHUN AJARAN 2019/2020
}

\author{
Zaimatuz Zakiyah \\ Universitas Islam Negeri Sunan Kalijaga Yogyakarta \\ zaimatuzzakiyah881137@gmail.com \\ Nurul Huda \\ Universitas Islam Negeri Sunan Kalijaga Yogyakarta \\ nurulhuda@uin-suka.ac.id
}

\begin{abstract}
As one component of language learning, the learning method becomes a determinant of the course of an effective and efficient learning process. This requires the professionalism of teachers to be able to implement certain methods in the learning process. The purpose of this paper is to determine the application of the Grammatical Hunting language game method, to find out students' responses to the learning methods applied, and their advantages and disadvantages in learning Arabic in class 3/1 Mutawasith Khoiriyah Wittaya Mulnithi Betong, Yala, Thailand. This research is a descriptive quantitative research. The sample of this research is students of class 3/1 Mutawasith Khoiriyah Wittaya Mulnithi Betong, Yala, Thailand was 25 students. The research technique applied was a non-test technique with data collection instruments in the form of observation, interviews, questionnaires, and documentation. The results showed that (1) The application of the Grammatical Hunting language game method consisted of 3 stages, namely: introduction, core activities, and closing. (2) Students show the best responses to the methods applied in the form of increased interest and activeness in learning Arabic, that is 89,77 \%. (3) The advantages of this method are eliminating boredom, creating cooperation, and supportive between students, while the disadvantages of applying this method, namely the number of groups and the crowded class.
\end{abstract}

Keywords: Grammatical Hunting language game methods, Arabic learning, interests, activeness.

\begin{abstract}
Abstrak: Sebagai salah satu komponen pembelajaran bahasa, metode pembelajaran menjadi penentu jalannya sebuah proses pembelajaran yang efektif dan efisien. Hal ini menuntut profesionalitas guru agar mampu mengimplementasikan metode tertentu dalam proses pembelajaran. Tujuan tulisan ini adalah untuk mengetahui penerapan metode permainan bahasa Grammatical Hunting, mengetahui respon siswa terhadap metode pembelajaran yang diterapkan, dan kelebihan serta kekurangannya dalam pembelajaran bahasa Arab di kelas 3/1 Mutawasith Khoiriyah Wittaya Mulnithi Betong, Yala, Thailand. Penelitian ini adalah penelitian kuantitatif deskriptif. Sampel dari penelitian ini adalah siswa kelas 3/1 Mutawasith Khoiriyah Wittaya Mulnithi Betong, Yala, Thailand yang berjumlah 25 siswa. Teknik penelitian yang diterapkan adalah teknik non tes dengan instrumen pengumpulan data berupa observasi, wawancara, kuisioner, dan dokumentasi. Hasil penelitian menunjukkan bahwa (1) Implementasi metode permainan bahasa Grammatical Hunting terdiri atas 3 tahap, yaitu: pendahuluan, kegiatan inti, dan penutup. (2) Siswa menunjukkan respon yang sangat baik terhadap metode yang diterapkan berupa minat dan keaktifan dalam mengikuti proses pembelajaran bahasa Arab, yaitu sebesar 89,77 \%. (3) Kelebihan dari metode ini adalah menghilangkan kebosanan, menimbulkan kerja sama, dan persaingan yang sehat antar siswa, sedangkan kekurangan dari penerapan metode ini, yaitu jumlah kelompok dan kelas yang ramai.
\end{abstract}

Kata kunci: Metode permainan bahasa Grammatical Hunting, Pembelajaran Bahasa Arab, minat, keaktifan. 


\section{PENDAHULUAN}

Bahasa Arab merupakan cabang dari ilmu agama, sehingga pembelajaran bahasa Arab di madrasah mutlak diperlukan. Bahasa ini merupakan salah satu syari'at agama yang seharusnya dimengerti oleh semua orang Islam. Karena pedoman seorang muslim adalah al-Qur'an dan al-Hadis yang berbahasa Arab. Oleh karena itu, bahasa Arab sudah semestinya diajarkan di madrasah dari jenjang dasar sampai tingkat atas. ${ }^{1}$

Pembelajaran bahasa Arab sebagai suatu sistem dapat dikelompokan kepada dua bagian, yaitu sistem pembelajaran bahasa Arab yang bertujuan pada penguasaan bahasa sebagai ujaran secara langsung, serta sistem pembelajaran bahasa Arab yang bertujuan pada gramatika. ${ }^{2}$ Kedua sistem pembelajaran tersebut melibatkan komponen-komponen pembelajaran dalam pelaksanaanya, salah satu komponen tersebut yaitu komponen metode pembelajaran.

Dalam Kamus Besar Bahasa Indonesia, metode berarti cara teratur yang digunakan untuk melaksanakan suatu pekerjaan agar tercapai sesuai dengan yang dikehendaki. ${ }^{3}$ Ahmad Janan Asifudin menuliskan dalam bukunya bahwa metode berarti jalan menuju ke tujuan tertentu. Menurutnya lagi, metode adalah cara yang teruji bila digunakan bagi objek pekerjaan tertentu lebih efektif dalam mencapai tujuan dan prosesnya relatif lebih efisien. ${ }^{4}$ Pendapat ini tidak jauh berbeda dengan yang disampaikan oleh Syamsuddin Asyrofi, bahwa metode pembelajaran mencakup perencanaan dan segala upaya yang bisa ditempuh dalam rangka pencapaian tujuan belajar-mengajar yang efektif dan efisien dan guru diharuskan memilih metode pembelajaran tertentu dalam menyampaikan materi pembelajaran. $^{5}$

1 Latifah Rahmawati, “Metode Musabaqah Bithaqah Mukhtalithul Kalimah 'MBMK' untuk Meningkatkan Hasil Belajar Maharah Al-Kitabah Siswa Kelas X D MAN 1 Yogyakarta," Al Mahara: Jurnal Pendidikan Bahasa Arab, Vol. 4, No. 2, 2018, 285-308.

2 Imaduddin Sukamto dan Ahmad Munawari, Tata Bahasa Arab Sistematis: Pendekatan Baru Mempelajari Tata Bahasa Arab, (Yogyakarta: Nurma Media Idea, 2018).

${ }^{3}$ Kbbi.web.id, "Kamus Besar Bahasa Indonesia." Online. https://kbbi.web.id/metode.html, diakses pada 19 September 2019.

4 Ahmad Janan Asifudin, Mengungkit Pilar-Pilar Pendidikan Islam, Cetakan Kedua (Yogyakarta: SUKA-Press UIN Sunan Kalijaga, 2010), 131-132.

5 Samsuddin Asyrofi, Metodologi Pengajaran Bahasa Arab: Konsep dan Implementasinya, (Yogyakarta: Penerbit Ombak, 2016), 18. 
Aishah Dahakeng memaparkan dalam sesi wawancara yang dilakukan pada di ruang majelis guru Khoiriyah Wittaya Mulnithi Betong, Yala, Thailand bahwa terdapat beberapa kendala dalam pembelajaran bahasa Arab di kelas 3/1 Mutawasith Khoiriyah Wittaya Mulnithi Betong, Yala, Thailand, ${ }^{6}$ antara lain: 1) Perhatian siswa kelas 3/1 Mutawasit Khoiriyah Wittaya Mulnithi Betong, Yala, Thailand pada pelajaran masih terbilang kurang, karena proses pembelajaran berlangsung ada siswa yang memperhatikan, ada pula yang tidak memperhatikan penjelasan guru; 2)Daya tangkap siswa pun masih terbilang rendah, ini dikarenakan siswa tidak memiliki dasar bahasa Arab; 3)Pada saat metode reading aloud diterapkan siswa yang tidak bisa membaca cukup banyak sehingga menghambat efektifitas dan efisiensi proses pembelajaran bahasa; 4)Problema diatas menyebabkan siswa tidak berminat untuk mengulang-ulang pelajaran yang telah diajarkan, sehingga siswa mudah lupa akan pelajaran yang telah mereka pelajari.

Kendala-kendala di atas, dibuktikan oleh hasil observasi pada proses pembelajaran bahasa Arab di Khoiriyah Wittaya Mulnithi yang cenderung menggunakan metode pembelajaran yang berpusat pada guru, yaitu metode ceramah. ${ }^{7}$ Hal ini berdampak pada: 1) Siswa kurang aktif dalam pelaksanaan pembelajaran bahasa Arab dan lebih banyak mendengarkan penjelasan guru; 2) Siswa menganggap bahasa Arab sebagai mata pelajaran yang rumit, sehingga siswa kurang berminat utuk mempelajari bahasa Arab; 3) Siswa menganggap bahasa Arab sebagai mata pelajaran yang membosankan.

Fenomena tersebut menuntut suatu pengetahuan, pemilihan, penerapan, serta pengelolaan metode pembelajaran yang bervariasi untuk mengatasi problematika yang ada. Diantara metode pembelajaran yang dapat diterapkan dalam pembelajaran qawā'id adalah metode permainan bahasa. Permainan berasal dari kata "main" yang berarti perbuatan untuk menyenangkan hati yang dilakukan menggunakan alat-alat kesenangan atau tanpa media. ${ }^{8}$

${ }^{6}$ Aishah Dahakeng, Guru bahasa Arab kelas 3 Mutawasith dan 4 Tsanawi Khoiriyah Wittaya Mulnithi Betong, Thailand, "Wawancara Terstruktur", pada 17 September 2019.

7 "Hasil Observasi", n.d, pada tanggal 29 Juli 2019.

${ }^{8}$ Abdul Wahab Rosyidi, Media Pembelajaran Bahasa Arab, (Malang: UIN-Malang Press, 2009), 80. 
Adapun dalam konteks bahasa, permainan berarti suatu aktivitas untuk memperoleh suatu keterampilan bahasa tertentu dengan cara yang menggembirakan. Permainan bahasa termasuk sarana pengajaran baru dalam pengajaran bahasa Arab yang digunakan sebagai langkah pendekatan dalam pembelajarannya. ${ }^{9}$ Jadi, dapat disimpulkan bahwa metode permainan bahasa adalah cara memperoleh suatu keterampilan bahasa tertentu menggunakan sarana penggajaran yang menyenangkan.

Imam Asrori mengutip pendapat Hidayat dan Tatang dalam bukunya yang berjudul "1000 Permainan Penyegar Pembelajaran Bahasa Arab" tentang urgensi permainan dalam proses pembelajaran bahasa yang didasarkan kepada beberapa pemikiran ${ }^{10}$, yaitu: permainan mampu menghilangkan rasa bosan, memberikan tantangan untuk memecahkan masalah dalam suasana gembira, menimbulkan semangat kerja sama, menimbulkan persaingan yang sehat antar siswa, membantu siswa agar lebih termotivasi, dan mendorong guru untuk selalu kreatif.

Salah satu metode permainan bahasa yang dapat diimplementasikan dalam pembelajaran bahasa Arab, khususnya qawā'id adalah metode Grammatical Hunting. Metode ini dalam bahasa Indonesia disebut Berburu Gramatika ini bertujuan untuk menemukan gramatika diantara huruf yang acak dengan menggunakan kata-kata yang telah disusun dalam satu kotak atau tabel. Selain itu, permainan ini dapat memacu siswa dalam mengembangkan gramatika melalui imajinasi dengan menggabungkan satu kata dengan kata yang lain. ${ }^{11}$

Peneliti memilih jenis metode permainan bahasa Grammatical Hunting yang dilaksanakan secara berkelompok karena metode ini merupakan metode yang tepat bagi siswa dalam memahami dan menyerap materi yang telah ditentukan, yang dalam hal ini adalah Al-Jumlah Al-Fi 'liyyah Al-Lāzim. Selain itu, jumlah siswa kelas 3/1 Mutawasith Khoiriyah Wittaya Mulnithi Betong, Yala, Thailand berjumlah cukup banyak, yaitu sejumlah 25 orang. Oleh karena itu, permainan ini pun dibentuk seperti sebuah pertandingan karena bentuk permainan ini akan

9 Nanang Kosim, Strategi dan Metodologi Pengajaran Bahasa Arab, (Bandung: CV. Arfino Raya, 2016), 125.

10 Imam Asrosi, 1000 Permainan Penyegar Pembelajaran Bahasa Arab. (Malang: CV. Bintang Sejahtera, 2017) , 3.

11 Fathul Mujib dan Nailur Rahmawati, Permainan Edukatif Pendukung Pembelajaran Bahasa Arab (2). Cetakan Kedua (Yogyakarta: DIVA Press, 2013), 172-173.

Lil 
memupuk persaingan sehat antar siswa dan mereka pun belajar bekerja sama dalam suatu pekerjaan.

Berdasarkan pemaparan di atas, peneliti tertarik untuk mengemas pembelajaran bahasa Arab yang menarik bagi siswa kelas 3/1 Mutawasith Khoiriyah Wittaya Mulnithi Betong, Yala, Thailand menggunakan suatu metode yang dapat menciptakan kegiatan pembelajaran yang menyenangkan dengan metode pembelajaran yang berpusat pada siswa, yaitu metode permainan bahasa Grammatical Hunting untuk mengetahui penerapan, respon siswa, dan kelebihan serta kekurangan penerapan metode permainan bahasa Grammatical Hunting di kelas 3/1 Mutawasith Khoiriyah Wittaya Mulnithi Betong, Yala, Thailand.

\section{METODE PENELITIAN}

Jenis pendekatan yang digunakan dalam penelitian ini adalah pendekatan kuantitatif. Pendekatan ini disebut sebagai pendekatan kuantitatif karena data penelitian yang dikumpulkan merupakan data berupa angka dan menggunakan analisis statistik. ${ }^{12}$ Data tersebut terdiri dari data primer dan data sekunder. Data primer dari penelitian ini, yaitu guru bahasa Arab dan siswa kelas 3/1 Mutawasith Khoiriyah Wittaya Mulnithi Betong, Yala, Thailand yang hasilnya diperoleh dari pengumpulan data berupa observasi, wawancara, kuisioner, dan dokumentasi. Adapun data sekundernya adalah buku, jurnal atau karya ilmiah, internet, yang relevan dengan penelitian ini.

Peneliti mengumpulkan data dengan menggunakan prosedur-prosedur non tes, yaitu: observasi partisipan pada 29 Juli 2019, yang mana peneliti terlibat dalam kegiatan pembelajaran untuk mengamati respon siswa terhadap metode yang diterapkan dan mendapatkan hasil yang lebih akurat dan tidak dapat disangkal. ${ }^{13}$ Selanjutnya, peneliti melakukan wawancara semi terstruktur dengan mengajukan beberapa pertanyaan untuk dimintai penjelasaannya kepada narasumber pada 17 September 2019.14 Kemudian, pada tanggal yang sama, peneliti menggunakan kuisioner tertutup untuk memperoleh data mengenai

12 Sugiyono, Metode Penelitian Pendidikan: Pendekatan Kuantitatif, Kualitatif, dan R\&D, (Bandung: Alfabet, 2012), 13.

13 Endang Mulyatiningsih, Metode Penelitian Terapan Bidang Pendidikan, (Yogyakarta: Alfabeta, 2013), 27.

14 Endang Mulyatiningsih, Metode..., 32.

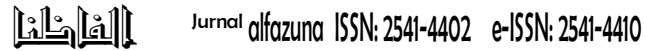


respon siswa terhadap metode pembelajaran yang diterapkan. Selain itu, peneliti menggunakan dokumentasi untuk melengkapi data penelitian.

Suharsimi Arikunto menyebutkan bahwa analisis merupakan proses sistematis yang digunakan untuk menyajikan hasil temuan kepada orang lain. ${ }^{15}$ Data yang telah terkumpul dianalisis dengan statistik deskriptif yang dituangkan ke dalam tabel untuk menggambarkan pembagian frekuensi dari setiap indikator kuisioner. Kemudian, untuk memperoleh distribusi persentase, data dihitung menggunakan rumus sebagai berikut: 16

$$
p=\frac{f}{N} \times 100 \%
$$

Keterangan:

F : Frekuensi yang sedang dicari persentasenya.

$\mathrm{N}$ : Number of Cases (jumlah frekuensi/ banyaknya individu)

$\mathrm{P}$ : Angka persentase

Setelah menggambarkan data dalam bentuk tabel, peneliti menyajikan data tersebut ke dalam grafik untuk memperlihatkan gambaran menyeluruh tentang perbandingan dari data yang ada dan memberikan informasi secara ringkas dan mudah dimengerti. ${ }^{17}$

\section{HASIL PENELITIAN DAN PEMBAHASAN}

Implementasi Metode Permainan Bahasa Grammatical Hunting di Kelas 3/1 Khoiriyah Wittaya Mulnithi Betong, Yalla, Thailand

Proses pembelajaran qawā'id di kelas 3/1 Khoiriyah Wittaya Mulnithi Betong, Yalla, Thailand terbagi menjadi 3 tahap, antara lain:

Pendahuluan

Pada tahap ini, guru memberi salam, memulai pelajaran dengan mengucapkan basmalah bersama-sama dan menanyakan kabar siswa. Selanjutnya, guru memeriksa kesiapan siswa dengan membacakan absensi kelas terlebih dahulu untuk mengetahui jumlah siswa yag hadir dan memberikan ice breaking. Kemudian, guru mendiskusikan pelajaran yang telah lalu yang berkaitan dengan

15 Suharsimi Arikunto, Prosedur Penelitian Suatu Pendekatan Praktik, (Jakarta: RINEKA Cipta, 2013), 85.

16 Anas Sudjiono, Pengantar Statistik Pendidikan, (Jakarta: PT. Raja Grafindo, 2015), 43.

17 Mahdiyah, Statistik Pendidikan, (Bandung: pt Remaja Rosdakarya Offset, 2016), 27. 
pelajaran yang akan diajarkan bersama siswa, yaitu tentang isim, fi 'il, dan huruf. Selanjutnya, guru melakukan apersepsi untuk mengetahui pengetahuan awal siswa tentang Al-Jumlah Al-Fi liyyah Al- Lāzim yang akan dibahas hari itu, serta menyampaikan tujuan pembelajaran dan garis besar cakupan materi, yaitu memahami kaidah bahasa Arab tentang Al-Jumlah Al-Fi liyyah Al- Lāzim. Sebelum menyampaikan materi, guru menyampaikan akan ada permainan dan latihan sebagai teknik penilaian setelah materi disampaikan.

Kegiatan inti

Dalam kegiatan inti, guru menjelaskan kaidah bahasa Arab tentang AlJumlah Al-Fi liyyah Al- Lāzim. Kemudian, siswa diarahkan untuk menanyakan kaidah bahasa Arab tentang Al-Jumlah Al-Fi liyyah Al-Lāzim yang belum dipahaminya. Setelah itu, guru meminta siswa untuk memberikan contoh AlJumlah Al-Fi 'liyyah Al- Lāzim. Lalu, guru membagi siswa menjadi dua kelompok (kelompok namlun dan kelompok fi $(i)$, serta mengatur tempat duduk dan tata letak kelas. Sebelum permainan dimulai, guru menjelaskan kepada siswa tentang langkah-langkah metode permainan bahasa Grammatical Hunting yang akan dimainkan bersama-sama.

Dilanjutkan dengan proses pelakasanaan permainan, yaitu guru menyebutkan terjemahan dari kalimat yang akan dicari siswa di dalam kotak. (satu kalimat terdiri dari dua kata, yaitu $f i$ 'il dan $f \bar{a}$ ' $i l$ ). Lalu, siswa mendiskusikan gramatkan yang hilang dalam kalimat yang telah disediakan dan secara beragantian mencari potongan kata di dalam kotak. Jika siswa kesulitan menerjemahkannya ke dalam bahasa Arab, maka siswa dapat melihat tabel kosa kata yang terletak dibawah tabel pencarian. Siswa yang telah mendapatkan potongan kata yang dicari kembali ke meja kelompok untuk menyusun dan menempelkan potongan kata tersebut ke dalam kalimat bersama dengan timnya. Siswa yang menyelesaikan tahap mencari, menyusun, dan menempelkan potongan kata mengangkat tangan sebagai tanda telah menyelesaikan tugas.

Lalu, Guru bersama siswa yang lain mengoreksi hasil kerja kelompoknya. Jika ternyata salah, kedua kelompok masih berkesempatan menyelesaikan tugasnya hingga menemuakan kata yang benar. Jika satu kelompok berhasil menyusun satu kalimat, maka dilanjutkan kepada kalimat berikutnya dan guru 
mencatat hasil yang diperoleh kelompok. Selanjutnya, guru dan siswa mendiskusikan hasil permainan da memberikan reward kepada kelompok yang menang.

\section{Penutup}

Setelah permainan selesai, guru dan siswa menyimpulkan materi yanngt elah dibahas. Kemudian, guru memberi latihan (tadrīb) untuk mengetahui penguasaan siswa terhadap kaidah Al-Jumlah Al-Fi 'iliyah Al- Lāzim. Setelah itu, guru mengakhiri jam pelajaran tersebut dengan membaca hamdalah dan mengucapkan salam sebelum keluar kelas.

\section{Analisis Lembar Kuisioner Siswa Kelas 3/1 Mutawasith Khoiriyah Wittaya Mulnithi Betong, Yala, Thailand}

Teknik analisis yang digunakan adalah statistik deskriptif menggunakan skala likert yang merupakan suatu skala psikometrik yang umum digunakan dalam angket dan merupakan skala yang paling banyak digunakan dalam riset berupa survei. Nama skala ini diambil dari nama Rensis Likert, yang menerbitkan suatu laporan yang menjelaskan penggunaannya. ${ }^{18}$

Ada 4 aspek yang direspon siswa dalam lembar kuisioner, yaitu: rasa ingin tahu, rasa senang, perhatian, dan partisipasi. 4 hal ini mengacu kepada minat dan keaktifan siswa selama pembelajaran berlangsung. Dari 25 lembar kuisioner yang disebar, ada 22 siswa yang menjadi responden. Indikator di atas diukur dengan bobot nilai 4 = sangat setuju, $3=$ setuju, 2 = kurang setuju, dan $1=$ tidak setuju dengan persentase skor 1-25\%= kurang, 26-50 \% = cukup, 51-75\%= baik, dan $76-100 \%=$ sangat baik. Analisis dari respon siswa tersebut adalah sebagai berikut:

Tabel 1. Hasil Kuisioner Minat dan Keaktifan Siswa terhadap Proses Pembelajaran Bahasa Arab Menggunakan Metode Permainan Bahasa

18Wikipedia: Ensiklopedia Bebas, “Skala Likert.” https://id.wikipedia.org/wiki/Skala Likert [24 September 2019] 


\section{Grammatical Hunting}

\begin{tabular}{|c|c|c|c|c|c|c|}
\hline NO & Aspek & Indikator & ST & $\mathbf{T}$ & KS & TS \\
\hline \multirow[t]{2}{*}{1} & \multirow[t]{2}{*}{$\begin{array}{l}\text { Rasa ingin } \\
\text { tahu }\end{array}$} & $\begin{array}{l}\text { saya ingin tahu lebih banyak } \\
\text { tentang pelajaran bahasa } \\
\text { Arab }\end{array}$ & $\begin{array}{c}17 \\
\text { siswa }\end{array}$ & $\begin{array}{c}5 \\
\text { Siswa }\end{array}$ & - & - \\
\hline & & \begin{tabular}{ll}
\multicolumn{2}{l}{ Saya antusias saat mengikuti } \\
kegiatan & pembelajaran \\
bahasa Arab &
\end{tabular} & $\begin{array}{c}13 \\
\text { siswa }\end{array}$ & $\begin{array}{c}9 \\
\text { siswa }\end{array}$ & - & - \\
\hline \multirow[t]{2}{*}{2} & \multirow[t]{2}{*}{ Rasa senang } & $\begin{array}{l}\text { Saya senang mengikuti } \\
\text { pelajaran bahasa Arab }\end{array}$ & $\begin{array}{c}19 \\
\text { Siswa }\end{array}$ & $\begin{array}{c}3 \\
\text { siswa }\end{array}$ & - & - \\
\hline & & Saya datang tepat waktu & $\begin{array}{c}21 \\
\text { siswa }\end{array}$ & $\begin{array}{c}1 \\
\text { Siswa }\end{array}$ & - & - \\
\hline \multirow[t]{2}{*}{3} & \multirow[t]{2}{*}{ Perhatian } & $\begin{array}{l}\text { Saya memperhatikan } \\
\text { pelajaran ketika guru } \\
\text { menyampaikan } \\
\text { pembelajaran bahasa Arab }\end{array}$ & $\begin{array}{c}3 \\
\text { siswa }\end{array}$ & $\begin{array}{c}19 \\
\text { Siswa }\end{array}$ & - & - \\
\hline & & $\begin{array}{l}\text { Saya tidak ramai sendiri } \\
\text { saat mengikuti kegiatan } \\
\text { pembelajaran }\end{array}$ & 21 & 1 & - & - \\
\hline \multirow[t]{2}{*}{4} & \multirow[t]{2}{*}{ Partisipatif } & $\begin{array}{l}\text { Saya aktif bertanya di dalam } \\
\text { kelas }\end{array}$ & $\begin{array}{c}5 \\
\text { Siswa }\end{array}$ & $\begin{array}{c}17 \\
\text { Siswa }\end{array}$ & - & - \\
\hline & & $\begin{array}{l}\text { Saya dapat menjawab } \\
\text { pertanyaan dari guru }\end{array}$ & $\begin{array}{c}6 \\
\text { siswa }\end{array}$ & $\begin{array}{c}15 \\
\text { siswa }\end{array}$ & $\begin{array}{c}1 \\
\text { siswa }\end{array}$ & - \\
\hline
\end{tabular}

Terdapat 8 indikator yang digunakan untuk mengukur respon siswa terhadap metode permainan bahasa Grammatical Hunting. Berdasarkan indikator 1, sebanyak 17 siswa (77 \%) menyatakan sangat setuju untuk ingin tahu lebih banyak tentang pelajaran bahasa Arab melalui metode yang diterapkan dan 5 siswa (23\%) menyatakan setuju.

\section{Gambar 1. Respon Siswa Terhadap Indikator 1}

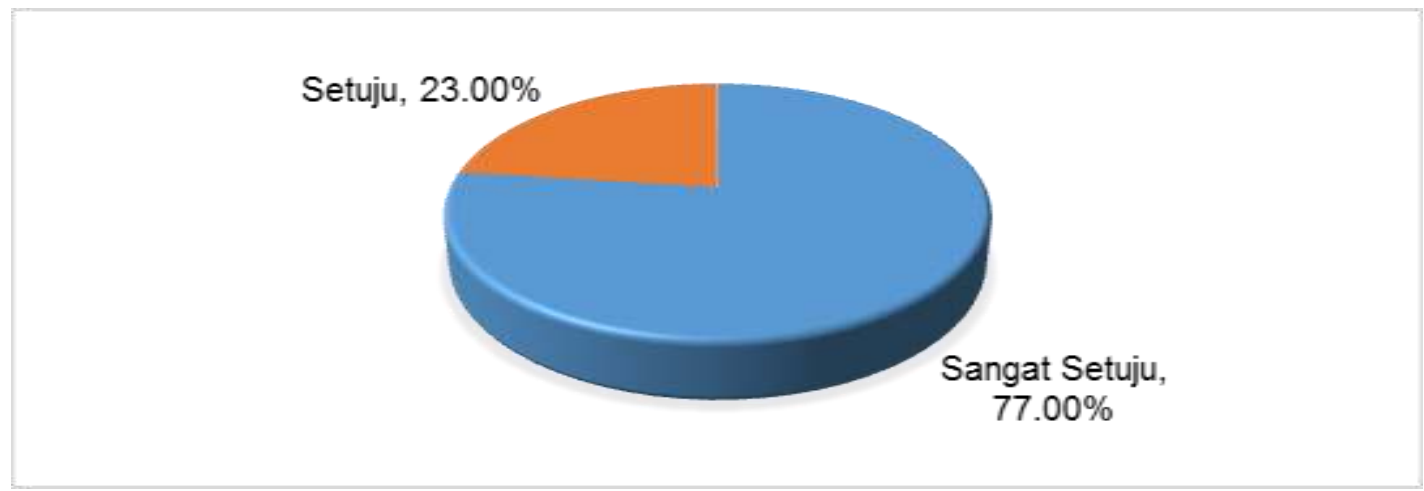

Pada indikator 2 yang mengukur antusiasme siswa pada saat mengikuti kegiatan pembelajaran bahasa Arab menggunakan metode permainan bahasa 
Grammatical Hunting diketahui bahwa sejumlah 13 siswa ( 59 \%) menyetakan sangat setuju dan sejumlah 9 siswa (40 \%) menyatakan setuju. Hal ini sejalan dengan hasil penelitian Wulan Indah Putri yang menunjukkan bahwa menggunakan metode permainan bahasa dapat menimbulkan semangat dan antusiasme siswa dalam pembelajaran bahasa Arab. ${ }^{19}$

\section{Gambar 2. Respon Siswa Terhadap Indikator 2}

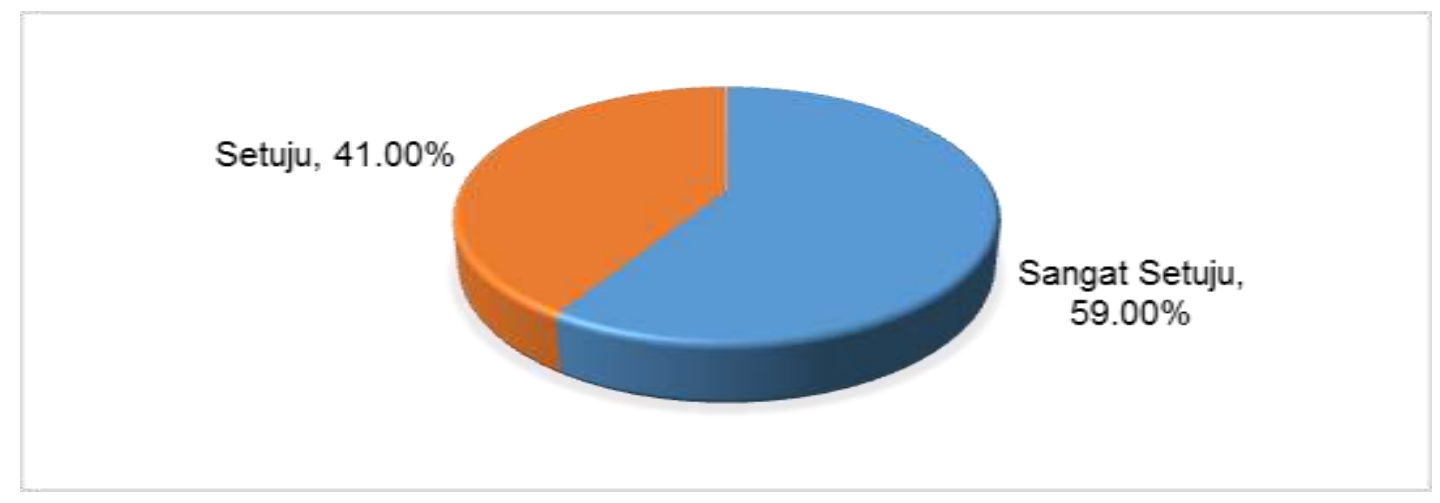

Kemudian, sebanyak 19 siswa (86 \%) sangat setuju dengan pernyataan pada indikator 3 yaitu siswa senang dalam mengikuti pembelajaran bahasa Arab dan sebanyak 3 siswa (14\%) menyatakan setuju dengan hal tersebut.

\section{Gambar 3. Respon Siswa Terhadap Indikator 3}

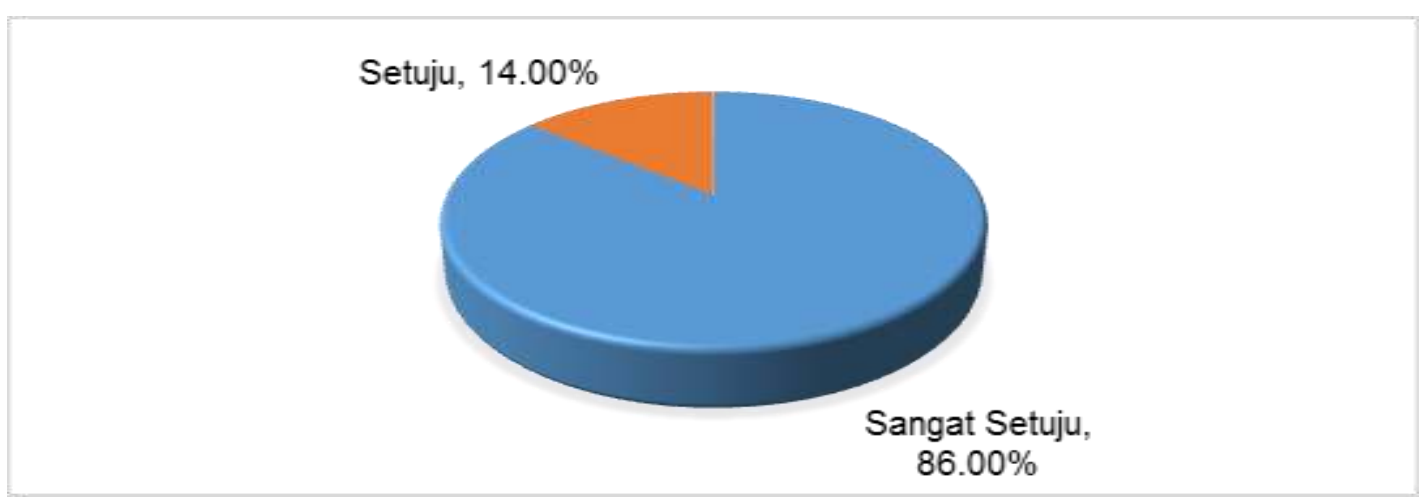

Selanjutnya, pada indikator 4 yaitu siswa datang tepat waktu memperoleh penilaian sangat setuju dari 21 siswa (95\%) dan 1 siswa (5\%) menyatakan setuju. Persentase yang sama terdapat pada indikator 6, yaitu siswa tidak ramai sendiri saat mengikuti kegiatan pembelajaran.

19 Wulan Indah Putri, "Kokami Language Game to Improve Arabic Speaking Ability", Alfazuna: Jurnal Pembelajaran Bahasa Arab dan Kebahasaaraban, Vol. 9 No. 1, 2015, 153-162.

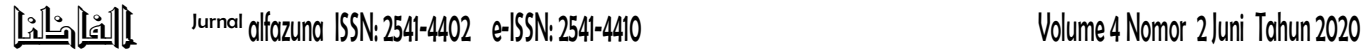




\section{Gambar 4. Respon Siswa Terhadap Indikator 4 dan 6}

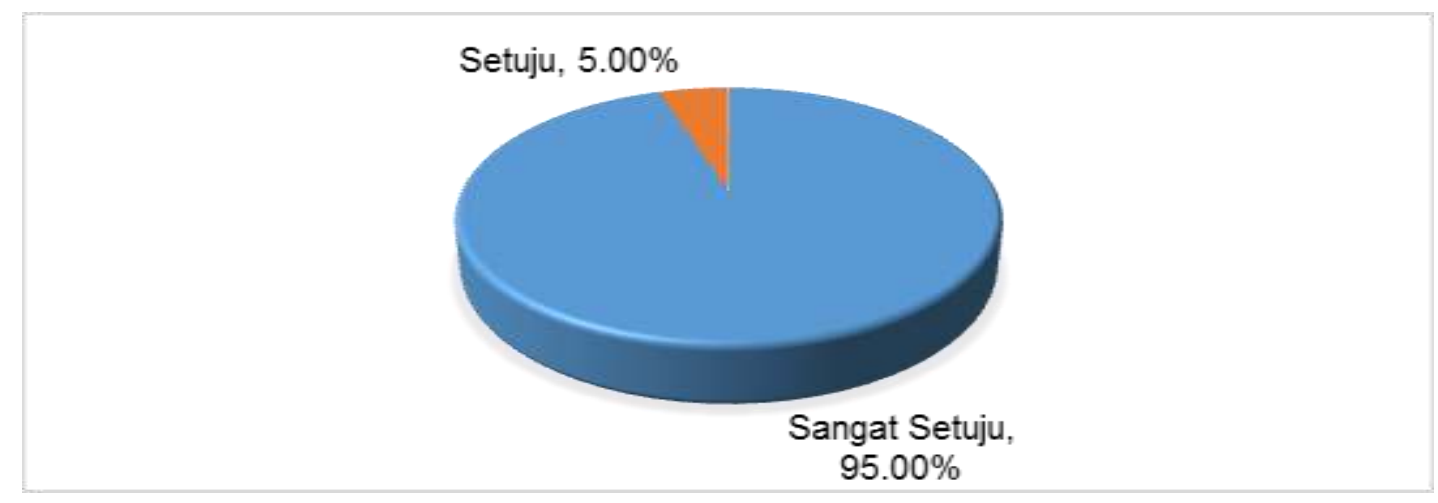

Sejumlah 3 siswa (14\%) menyatakan sangat setuju dengan indikator 5 yang meyatakan bahwa siswa memperhatikan ketika guru menyampaikan pembelajaran bahasa Arab dan sejumlah 19 siswa (86 \%) menyatakan setuju.

\section{Gambar 5. Respon Siswa Terhadap Indikator 5}

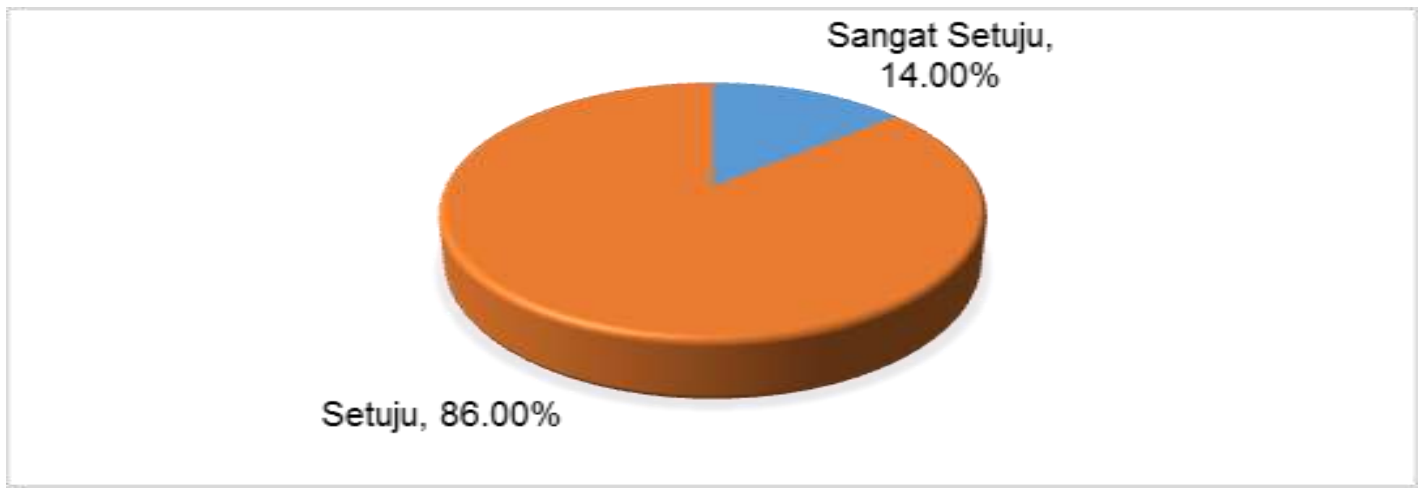

Pada indikator 7 yang mengukur keaktifan siswa dalam bertanya di dalam kelas mendapatkan hasil sangat setuju dari 5 siswa (22\%) dan 17 siswa lainnya (77\%) menyatakan setuju.

\section{Gambar 6. Respon Siswa Terhadap Indikator 7}

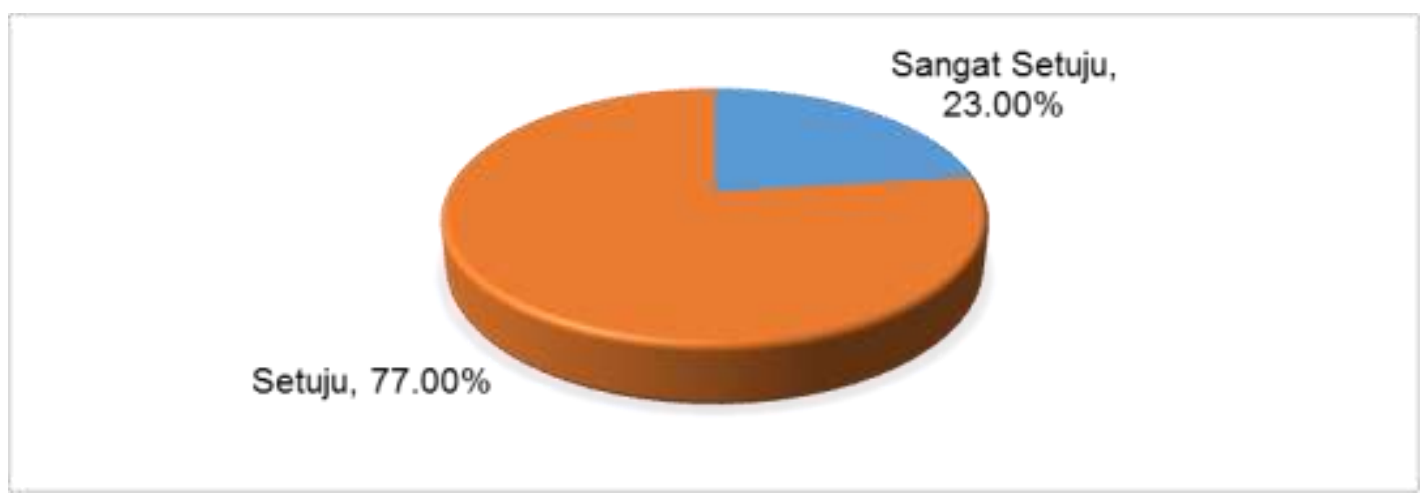

Kemudian, sebanyak 6 siswa (27 \%) menyatakan sangat setuju dengan indikator 8 yang mengukur kemampuan siswa dalam menjawab pertanyaan dari 
guru, sebanyak 15 siswa (68\%) menyatakan setuju, dan 1 siswa (5 \%) siswa menyatakan kurang setuju.

\section{Gambar 7. Respon Siswa Terhadap Indikator 8}

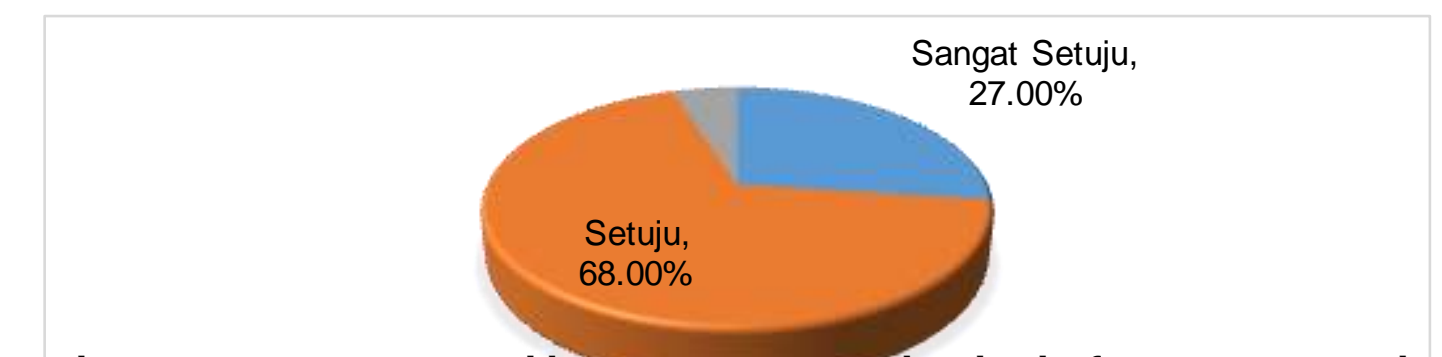

Hasil respon siswa menunjukkan varnmentat dan keaktifan yang sangat baik terhadap metode permainan bahasa Grammatical Hunting dengan total skor sejumlah 632 (89,77\% atau dibulatkan menjadi 90 \%) Hasil ini tak jauh berbeda dengan yang dituliskan oleh Marsiah bahwa metode bermain sangat menarik dan menyenangkan serta berpengaruh kepada keaktifan dan antusiasme siswa. ${ }^{20}$ Begitu juga dengan hasil penelitian yang ditemukan oleh Maspalah bahwa permainan berkontribusi dalam meningkatkan aktivitas siswa dalam proses pembelajaran. ${ }^{21}$

\section{Kelebihan dan Kekurangan Implementasi Metode Permainan Bahasa Grammatical Hunting di Kelas 3/1 Khoiriyah Wittaya Mulnithi Betong, Yalla,} Thailand

Setelah mengimplementasikan metode permainan bahasa Grammatical Hunting dalam pembelajaran bahasa Arab di kelas 3/1 Khoiriyah Wittaya Mulnithi Betong, Yala, Thailand, peneliti menemukan beberapa kelabihan dan kekurangan dalam penerapannya. Adapun kelebihannya, yaitu: 1) Metode permainan bahasa Grammatical Hunting dapat meningkatkan minat dan keaktifan siswa terhadap mata pelajaran bahasa Arab; 2) Metode permainan bahasa Grammatical Hunting dapat menghilangkan kebosanan siswa dalam mengikuti proses pembelajaran bahasa Arab; 3)Metode permainan bahasa Grammatical Hunting dapat menimbulkan semangat kerja sama dan persaingan yang sehat antar siswa.

20 Marsiah Fachri, "'Question Container" Game to Improve Arabic Ability for Beginner Learners", Alfazuna: Jurnal Pembelajaran Bahasa Arab dan Kebahasaaraban, Vol. 9 No. 1, 2015, 163174.

21 Maspalah, "Penggunaan Permainan Memasangkan kartu dalam Pembelajaran Bahasa Arab di SMA", Jurnal Pendidikan Bahasa dan Sastra, Vol. 13, No. 1, 2013.

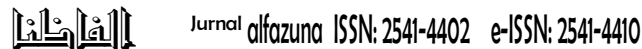


Sedangkan kekurangan dari penerapan metode ini, yaitu: 1) Jenis permainan dua kelompok, dirasa kurang efektif untuk 25 orang siswa. Sebaiknya, siswa dibagi dalam 3 kelompok, sehingga semua siswa dapat berperan dalam permainan; 2) Bentuk permainan yang dirancang seperti sebuah pertandingan, menyebabkan suasana kelas berlangsung ramai. Sehingga, guru terkadang kesulitan memberikan instruksi.

\section{KESIMPULAN}

Berdasarakan penelitian yang dilaksanakan di kelas 3/1 Khoiriyah Wittaya Mulnithi Betong, Yala, Thailand, dengan menggunakan metode permainan bahasa Grammatical Hunting, maka dapat disimpulkan bahwa: (1) ${ }^{22}$ Implementasi metode permainan bahasa Grammatical Hunting dalam pembelajaran bahasa Arab di kelas 3/1 Mutawasith Khoiriyah Wittaya Mulnithi Betong, Yalla, Thailand dilaksankan dalam 3 tahap, yaitu: pendahuluan, kegiatan inti dimana siswa melaksanakan permainan bahasa Grammatical Hunting, dan penutup. (2) Siswa kelas 3/1 Khoiriyah Wittaya Mulnithi Betong, Yala, Thailand, menunjukkan respon yang sangat baik terhadap metode permainan bahasa Grammatical Hunting. Hal ini dibuktikan oleh hasil analisis data kuantitatif terhadap minat dan keaktifan kelas tersebut sebesar 89,77 \%. (3) Kelebihan dari permainan ini adalah dapat mengatasi rasa bosan, menimbulkan semangat untuk kerja sama, dan persaingan yang sehat. Adapun kekurangan penerapan metode permainan bahasa ini yaitu pada jumlah kelompok permainan dan kondisi kelas yang berlangsun ramai pada saat proses pembelajaran berlangsung.

\section{DAFTAR PUSTAKA}

Anshori, Ahmad Muhtadi. Pengajaran Bahasa Arab: Media dan Metode-Metodenya. Yogyakarta: Penerbit TERAS, 2009.

Arikunto, Suharsimi. Prosedur Penelitian Suatu Pendekatan Praktik. Jakarta: RINEKA Cipta, 2013.

Asifudin, Ahmad Janan. Mengungkit Pilar-Pilar Pendidikan Islam. Cetakan Kedua Yogyakarta: SUKA-Press UIN Sunan Kalijaga, 2010. 
Asrori, Imam. 1000 Permainan Penyegar Pembelajaran Bahasa Arab. Malang: CV. Bintang Sejahtera, 2017.

Asyrofi, Samsuddin. Metodologi Pengajaran Bahasa Arab: Konsep dan Implementasinya. Yogyakarta: Penerbit Ombak, 2016.

Dahakeng, Aishah, Guru bahasa Arab kelas 3 Mutawasith dan 4 Tsanawi Khoiriyah Wittaya Mulnithi Betong, Thailand. "Wawancara Terstruktur", pada 17 September 2019.

Marsiah Fachri, "'Question Container" Game to Improve Arabic Ability for Beginner Learners", Alfazuna: Jurnal Pembelajaran Bahasa Arab dan Kebahasaaraban, Vol. 9 No. 1, 2015.

“Hasil Observasi”, pada 29 Juli 2019, n.d.

Kbbi.web.id. "Kamus Besar Bahasa Indonesia."Online. https://kbbi.web.id/metode.html, diakses pada 19 September 2019.

Kosim, Nanang. Strategi dan Metodologi Pengajaran Bahasa Arab. Bandung: CV. Arfino Raya, 2016.

Mahdiyah. Statistik Pendidikan. Bandung: PT Remaja Rosdakarya Offset, 2016.

Maspalah, "Penggunaan Permainan Memasangkan kartu dalam Pembelajaran Bahasa Arab di SMA", Jurnal Pendidikan Bahasa dan Sastra, Vol. 13, No. 1, 2013.

Mujib, Fathul dan Nailur Rahmawati. Permainan Edukatif Pendukung Pembelajaran Bahasa Arab (2). Cetakan Kedua Yogyakarta: DIVA Press, 2013.

Mulyatiningsih, Endang. Metode Penelitian Terapan Bidang Pendidikan. Yogyakarta: Alfabeta, 2013.

Putri, Wulan Indah. "Kokami Language Game to Improve Arabic Speaking Ability", Alfazuna: Jurnal Pembelajaran Bahasa Arab dan Kebahasaaraban, Vol. 9 No. $1,2015$.

Rahmawati, Latifah. Metode Musabaqah Bithaqah Mukhtalithul Kalimah 'MBMK' untuk Meningkatkan Hasil Belajar Maharah Al-Kitabah Siswa Kelas X D MAN 1 Yogyakarta." Al-Mahara: Jurnal Pendidikan Bahasa Arab, Vol. 4, No.2, 2018.

Rosyidi Abdul, Wahab dan Mamlu'atul Ni'mah. Memahami Konsep Dasar Pembelajaran Bahasa Arab. Malang: UIN Maliki Press, 2012.

Sudjiono, Anas. Pengantar Statistik Pendidikan. Jakarta: PT. Raja Grafindo, 2015.

Sugiyono. Metode Penelitian Pendidikan: Pendekatan Kuantitatif, Kualitatif, dan $R \& D$, Bandung: Alfabet, 2012. 
Sukamto, Imaduddin dan Ahmad Munawari. Tata Bahasa Arab Sistematis: Pendekatan Baru Mempelajari Tata Bahasa Arab. Yogyakarta: Nurma Media Idea, 2018.

Wikipedia: Ensiklopedia "Skala Bebas, Likert." https://id.wikipedia.org/wiki/Skala_Likert, diakses pada 24 September 2019] 